\title{
Motivational and Cognitive Learning Strategies Used by First-Year Engineering Undergraduate Students at Universidad Católica in Chile
}

\author{
María José Anais ${ }^{1}$, Ana María Hojas ${ }^{1}$, Angélica Bustos ${ }^{1}$, Cecilia Letelier ${ }^{1}$, \\ María Soledad Zuzulich ${ }^{1}$, Báltica Cabieses ${ }^{2}$, Marcela Zubiaguirre ${ }^{1}$ \\ ${ }^{1}$ Centro de Apoyo al Rendimiento Académico y de Exploración Vocacional, Pontificia Universidad Católica de \\ Chile, Santiago, Chile \\ ${ }^{2}$ Faculty of Medicine, Universidad del Desarrollo, Santiago, Chile \\ Email: manais@uc.cl
}

Received August 31 ${ }^{\text {st }}$ 2012; revised September 27 ${ }^{\text {th }}$, 2012; accepted October $14^{\text {th }}, 2012$

\begin{abstract}
The learning process is sensitive to the demands from the learning task and the specific subject of study. This study provides a characterization of the motivational and cognitive learning strategies used by students in their first year of an undergraduate Civil Engineering degree course at a prestigious Chilean university. The module considered for this study was "Introduction to Calculus", the first course in Mathematics that these students took at the beginning of their career. A sample of 339 students (73\% of the total students enrolled) attended the last lecture and consented to participate in this study lecture (no student rejected to participate). They answered the Motivated Strategies Learning Questionnaire (MSLQ). The MSLQ asked the students about the motivational and cognitive learning strategies that they applied in the selected module. Mean scores for motivational and cognitive items were categorized into low, medium or high values. Students reported high motivational strategies, particularly regarding their value of the task and their control of learning beliefs. These were ranked as "high" level. As for the cognitive learning strategies, they were also high but slightly lower than the motivational dimensions of the learning experience. Hence, they were ranked in an upper-middle range, excelling in meta-cognitive self-regulation and effort regulation. Moreover, motivational and cognitive strategies were interrelated components affecting the learning outcomes. This study explored self-reported motivational and cognitive learning strategies applied by first-year undergraduate students of a Civil Engineering degree course in one of the largest universities in Chile. Our findings suggest that both motivational and cognitive components of learning process are relevant and interact with each other. These results contribute to a better understanding of the learning process of engineering students in an early curricular stage. Hence, they provide relevant knowledge that could be applied in teaching and learning practices in higher education.
\end{abstract}

Keywords: Academic Learning Strategies; Motivational Skills; Undergraduate Students; Chile; Cross-Sectional Study

\section{Background}

The Support Center for Academic Performance and Career Exploration at the Pontificia Universidad Catolica de Chile (CARA-UC) seeks to promote and develop the wellbeing of students, emphasizing academic dimensions, as they constitute a protective factor for mental health (Susperreguy, Flores, Micin, \& Zuzulich, 2007). To meet this end, the Center provides services at the individual and group level, which are “learner-centered”, by strengthening students' academic skills in order to improve their learning process and related outcomes. In this center, students are considered to be their own promoters of a successful learning experience. It is important, therefore, to understand their cognitive and motivational strategies before the development of any educational and motivational intervenetion. Specifically, the team at CARA-UC constantly seeks to understand what the cognitive processes used by students are in a given context, and what aspects of any particular academic task motivate them to achieve their learning goals. The Center understands learning achievement as a variable that depends upon the interaction of multiple and inter-related factors, such as affect, cognition, resource management, motivation, and others (Hojas, Anais, Bustos, Letelier, \& Zuzulich, 2012). A better understanding of this learning process, especially at an early curricular stage, could provide relevant feedback to CARA-UC and the module lecturers, suggesting what motivational and cognitive processes could significantly improve their learning experience and performance.

Bearing in mind that the learning process is always sensitive to the demands from the task and the specific subject of study (González, Valle, Rodríguez, \& Piñeiro, 2002), this study seeks to understand motivational and learning strategies in the context of a particular topic, "Introduction to Calculus", among first year undergraduate students of the Civil Engineering degree course. To measure students' motivational and cognitive learning strategies we used the Motivated Strategies Learning Questionnaire (MSLQ) by Pintrich, Smith, Garcia and McKeachie (1991). This instrument has been widely used in similar studies, either in its full extent (Chi-Kin Lee, Yin, \& Zhang, 2010; Chiecher, Donolo, \& Rinaudo, 2007; Paoloni, 2009; Rinaudo, 
Chiecher, \& Donolo, 2003) or by specific items only (Rinaudo, De la Barrera \& Donolo, 2006), and it has proven to be a reliable instrument to investigate issues in the area of motivation and use of cognitive learning strategies, in a range of disciplines and different types of students (García \& McKeachie, 2005).

\section{The MSLQ Instrument to Assess Strategies and Motivation in Learning}

The MSLQ considers two key aspects of the learning process: motivational and cognitive. Each of these is described in the following paragraphs.

\section{Motivational Dimension}

Motivated students take advantage of the opportunities they have to optimize their learning. They are, therefore, more likely to persist and to find effective ways of dealing with harder tasks (Chiecher et al., 2007; Schunk \& Zimmerman, 2009). This is probably due to their ability to guide their academic behavior by framing the task within their existing cognitive resources, and choosing the type of strategy to use within such cognitive frame (Rinaudo et al., 2006). In educational settings, Pintrich \& García (1993) suggest three components that would be the basis for motivation: 1) Value; 2) Expectancy; and 3) Affect.

The Value component refers to the importance attributed by students to the learning utility and cost involved, in terms of time, effort or other such costs (Chiecher et al., 2007; Schunk \& Zimmerman, 2009). A greater appreciation of the task would correlate with greater use of cognitive strategies, leading to deep processing and better quality learning experiences (Chiecher et al., 2007; Schunk \& Zimmerman, 2009). Within this dimension, we can differentiate between the motivational orientation toward intrinsic goals and extrinsic goals. For intrinsic goals, the student performs an activity due to their own interest, the experience gained and the learning involved. It has been suggested that this type of orientation relates to patterns of cognition and motivation that favor learning (Pintrich, 2000; Chiecher et al., 2007). For extrinsic goals, the student performs a task due to the reward or profit associated with it. This would relate with superficial learning strategies, such as seeking quick solutions and making external causal attributions of performance (Rinaudo et al., 2006).

The Expectancy component includes two concepts: self-efficacy for learning and performance, and control of learning beliefs. Self-efficacy refers to individuals' beliefs about being able to execute the actions required to achieve a desired result in a course (Pintrich et al., 1991). Students with higher selfefficacy tend to be more motivated and make better use of existing learning strategies. They also tend to believe that if they persist and strive, they will then get a better result from their performance. The second concept of control of learning beliefs is also relevant to results (Pintrich \& García, 1993). In this respect, it has been recognized that when students have a greater perception of internal control, their effort and dedication is greater.

Finally, in terms of the Affective component, anxiety has been shown to affect motivation by the emergence of negative thoughts that create a barrier to the learning process. These tend to reflect a concern over performance and outcomes (Pintrich et al., 1991; Chiecher et al., 2007). According to Rinaudo et al. (2003), this dimension correlates negatively with the use of effective cognitive learning strategies by students.

\section{Cognitive Dimension}

As important as motivation, cognitive processes are developed throughout the learning process, allowing individuals the acquisition, processing, integration and retrieval of new and existing information (Rinaudo, 2003). This dimension includes two large components: 1) Cognitive and meta-cognitive strategies; and 2) Resource management strategies.

Within the cognitive and meta-cognitive strategies, the simplest possible strategy is "rehearsal". This is based on review, repetition or recitation techniques to facilitate the processes of attention, coding and retention of information at superficial memory levels. Rehearsal is useful for simple tasks and for the activation of the working memory (Pintrich et al., 1991). However, Nuñez, have pointed out how important it is that students take a deeper approach to learning, such as through forming relationships, applying content, or verifying theories. Such deeper approaches allude to more complex cognitive strategies such as those of "Elaboration" and "Critical Thinking” (Nuñez, 1995; Rinaudo et al., 2006). Elaboration allows students to build relationships between different learning points. It is classified as an intermediate-level strategy because it establishes relationships in the learning content, facilitating commitment to long-term memory. On a deeper level, Organization strategies allows further processing of information, as it includes the selection of the main interrelated ideas and organizes them into different categories. Organization involves modification of information and restructuring of knowledge through diagrams, classifications or comparisons (Pintrich et al., 1991). The strategy that allows individuals to achieve deeper understanding is Critical Thinking (Rinaudo et al., 2003). It establishes relationships between prior and new knowledge, leading to the ability to solve problems, make decisions and evaluations, and develop argumentative and reflective capacities (Pintrich \& García, 1993). Finally, meta-cognitive strategies include self-regulating and self-monitoring dimensions, such as attention, understanding, and action planning aimed at learning control. In this sense, self-regulated students would be active participants in their own learning process (Chiecher et al., 2007).

The Resource management component refers to the strategic management and regulation of resources that are relevant to achieve an effective learning experience. Examples of such resources are the time and the environment of study. Regulating these involves planning strategies that are based on achieving goals within an environment that facilitates mental focus and concentration. But along with this, strategic students regulate their effort and perseverance, which are very relevant for the fulfillment of goals, even when they are difficult or boring. Resource management also includes peer learning and help seeking, which are valuable skills for managing the support required from others.

\section{Purpose of This Study}

This study was developed by CARA-UC, in partnership with the Faculty of Engineering of the University. Its aim was to characterize first year undergraduate Engineering students, in terms of self-reported motivational and cognitive learning strategies used for the Introduction to Calculus module. These students are representative of high achieving early career undergraduates who have obtained the highest scores at the na- 
tional-A-level equivalent in the UK or SATs in the US-tests for the entire country. Understanding how these young students learn (through both motivational and cognitive processes) could serve as a significant input to enrich programmes and services aimed at strengthening educational interventions.

\section{Method}

\section{Participants}

All students attending the Introduction to Calculus module in 2011 were considered as the sampling universe. A sample of 339 students undertaking this module consented to participate and answered the Motivated Strategies Learning Questionnaire (MSLQ) at the end the module. The sample included every student attending the final lecture of the module $(73 \%$ of the total students enrolled). No student rejected participation. This module was taught in 4 parallel sections of about 80 students each. At the time this study was conducted, the rate of students successfully approving the module's exams was $77 \%$.

\section{Instrument}

We used the Motivated Strategies for Learning Questionnaire, MSLQ (Pintrich, Smith, García, \& McKeachie, 1991), translated to Spanish by Letelier, Lissi, Flores, \& Assef (2007), and adjusted by the research team at CARA-UC. The MSLQ is a self-report questionnaire that assesses motivational orientations and cognitive learning strategies of students in a specific course (Pintrich et al., 1991). Thus, from a cognitive social learning viewpoint it considers aspects that are both dynamic and contextually determined, with variations depending on the course and nature of the academic task under observation (García \& McKeachie, 2005).

This instrument has two sections of 31 items each. All questions offer a Likert scale type of response of 7 points, from 1 (not true) to 7 (very true). The application of the instrument takes, on average, 15 minutes. The Motivation section has six sub-scales and the Strategic Learning section has nine. To facilitate responses to the questionnaire in the context of this particular module, the research team added the following phrase at the beginning: "When the question refers to 'reading', it may be interpreted as relating to practicing and rehearsing mathematics exercises and mathematical study”.

\section{Procedures}

The questionnaire was answered during the final lecture. Students were invited to participate and to sign an informed consent form, in which it was outlined that their participation was voluntary and that their responses would be confidential. All students attending that last lecture accepted to participate.

\section{Data Analysis}

Continuous variables are shown as means and standard deviations, while categorical variables as the number of cases and percentages. Spearman's rank correlation coefficient was used to assess the linear relationship between two ordinal and/or numerical variables.

Cronbach's Alpha coefficient was used as a measure of internal consistency and reliability of the questionnaire. This was then compared to the original study from the US.
All $p$ values were two-tailed, and a value of $<0.05$ was considered to be statistically significant. Data processing and statistical analyses were done with the SPSS statistical software package version 15.0 (SPSS Inc., Chicago, IL, USA).

\section{Results}

\section{Reliability}

Results regarding the reliability of the MSLQ full questionnaire and its subscales and items appear in Table 1. It is noted that, with the exception of some small differences, the reliability of the MLSQ questionnaire in this study is very similar to that found in the original 1990 study, with 380 students of various subjects in Midwestern College (Pintrich et al., 1991).

\section{Motivational and Learning Strategies Used by Students of Introduction to Calculus Module}

We describe the results maintaining the distinction between sections of Motivation and Cognitive Learning Strategies, by analyzing the sub-scale scores according to the grouping of scales proposed by the authors (Pintrich et al., 1991). Whenever appropriate, specific reference is made to certain items that

Table 1.

Reliability of the MSLQ questionnaire, by subscales.

\begin{tabular}{|c|c|c|c|}
\hline \multicolumn{4}{|c|}{ Motivation scales } \\
\hline Subscale & $\mathrm{N}$ items & $\begin{array}{l}\text { Reliability } \\
\text { original } \\
\text { application }\end{array}$ & $\begin{array}{l}\text { Reliability this } \\
\text { study application, } \\
2011\end{array}$ \\
\hline Íntrinsic goal orientation & 4 & 0.74 & 0.76 \\
\hline Extrinsic goal orientation & 4 & 0.62 & 0.52 \\
\hline Task value & 6 & 0.90 & 0.88 \\
\hline Control beliefs & 4 & 0.68 & 0.74 \\
\hline $\begin{array}{l}\text { Self-efficacy for learning } \\
\text { and performance }\end{array}$ & 8 & 0.93 & 0.91 \\
\hline Test for anxiety & 5 & 0.80 & 0.68 \\
\hline \multicolumn{4}{|l|}{ Learning strategies scale } \\
\hline Rehearsal & 4 & 0.69 & 0.69 \\
\hline Elaboration & 6 & 0.76 & 0.74 \\
\hline Organization & 4 & 0.64 & 0.73 \\
\hline Critical thinking & 5 & 0.80 & 0.74 \\
\hline $\begin{array}{l}\text { Meta-cognitive } \\
\text { Self-regulation }\end{array}$ & 12 & 0.79 & 0.79 \\
\hline $\begin{array}{l}\text { Time and study } \\
\text { environment }\end{array}$ & 8 & 0.76 & 0.78 \\
\hline Effort regulation & 4 & 0.69 & 0.61 \\
\hline Peer learning & 3 & 0.76 & 0.63 \\
\hline Help seeking & 4 & 0.52 & 0.45 \\
\hline
\end{tabular}

Note: "(Pintrich et al., 1991). 
reflect interesting aspects of this group. In order to locate the observed group averages within expected minimum and maximum scores, three intervals were constructed for this study: high, medium and low ranks. As noted below, these students scored high on the sub-scale of Motivation (Tables 2 and 3).

\section{Motivational Dimension}

By characterizing the motivational profile of this group (Table 2) the highest mean values were in learning control beliefs $(\mathrm{M}=5.84, \mathrm{SD}=0.93)$ and task value $(\mathrm{M}=5.83, \mathrm{SD}=0.96)$. There was a lower mean for the extrinsic motivation component $(\mathrm{M}=4.68, \mathrm{SD}=1.07)$. Thus, it is possible to indicate that this group of students valued and/or perceived the Introduction to Calculus module as a useful subject. They also perceived that their efforts could lead them to positive results. Their learning process appeared to motivate them more than grades or other results, although the latter was still important to them. Findings for each component of the motivational dimension are explained in detail in the following paragraphs.

- Value component

Regarding the Task Value, over $80 \%$ of the students chose alternatives close to "very true" in virtually all items of this subscale. Specifically, $94.7 \%$ of students thought that it was important to learn the course material, and this item gave the highest mean to the motivation section as a whole $(M=6.33$, $\mathrm{SD}=0.92$ ). In addition, $87.6 \%$ of students considered that they could apply what they have learnt in this course to other courses. As for the reasons for performing the tasks of this course, this appeared to be slightly more determined by intrinsic goals $(M=5.1, S D=1.07)$ than extrinsic ones $(M=4.68$, $\mathrm{SD}=1.07)$. There was satisfaction in them "trying to understand the content as thoroughly as possible” $(\mathrm{M}=5.5, \mathrm{SD}=$ 1.31) and they preferred it when the class material was challenging, in that they could learn new things $(\mathrm{M}=5.36, \mathrm{SD}=$ 1.28). However, this interest decreased when the activity did not guarantee a good grade in the module $(\mathrm{M}=4.47, \mathrm{SD}=$ 1.49); $22 \%$ of students said they would prefer not to choose this type of activity that does not guarantee a good grade at the end. The extrinsic motivation subscale showed the lowest scores, even when $61 \%$ of the group agreed that the most important thing for them was to finish the semester with a good grade ( $M$ $=4.84, \mathrm{SD}=1.48$ ).

- Expectancy component

In the Control Beliefs subscale, 94\% agreed with the statement that if they study the subject appropriately $(\mathrm{M}=6.30, \mathrm{SD}=$ $1.01)$ and put enough effort into it $(M=6.19, S D=1.02)$ then they would learn the course material. However, a lower level of agreement was observed when they were asked whether it was their fault if they did not learn the course material adequately ( $M=5.41, S D=1.47$ ) or whether a lower degree of understanding of the subject was due to them not trying hard enough to learn the material $(\mathrm{M}=5.51, \mathrm{SD}=1.40)$. The Self-Efficacy subscale for Learning and Performance showed a greater variation in student

Table 2.

Descriptive statistics of the motivational component.

\begin{tabular}{cccccccc}
\hline Component. & Subscale & $\mathrm{N}$ & Mean & SD & Variance & Range \\
\hline \multirow{2}{*}{ Value component } & Intrinsic goal orientation & 339 & 5.1 & 1.07 & 1.16 & High \\
& Extrinsic goal orientation & 339 & 4.68 & 1.07 & 1.16 & High & High \\
& Task value & 339 & 5.83 & 0.96 & 0.93 & High \\
Expectancy component & Control beliefs & 339 & 5.84 & 0.93 & 0.87 & High \\
Affective component & Self-efficacy for learning and performance & 339 & 5.01 & 1.07 & 1.14 & 1.25 & Medium \\
\hline
\end{tabular}

Table 3.

Descriptive statistics of cognitive strategies.

\begin{tabular}{|c|c|c|c|c|c|c|}
\hline Component & Subscale & $\mathrm{N}$ & Mean & SD & Variance & Range \\
\hline \multirow{5}{*}{$\begin{array}{l}\text { Cognitive and meta-cognitive } \\
\text { strategies component }\end{array}$} & Rehearsal & 339 & 3.95 & 1.24 & 1.54 & Medium \\
\hline & Elaboration & 339 & 4.6 & 1.1 & 1.22 & Medium \\
\hline & Organization & 339 & 4.17 & 1.38 & 1.9 & Medium \\
\hline & Critical thinking & 339 & 4.51 & 1.1 & 1.2 & Medium \\
\hline & Meta-cognitive self-regulation & 339 & 4.85 & 0.84 & 0.71 & High \\
\hline \multirow{4}{*}{ Resource management strategies } & Time and study environment & 339 & 4.75 & 1.04 & 1.08 & High \\
\hline & Effort regulation & 339 & 5.21 & 1.05 & 1.11 & High \\
\hline & Peer learning & 339 & 4.39 & 1.29 & 1.66 & Medium \\
\hline & Help seeking & 339 & 4.4 & 1.06 & 1.12 & Medium \\
\hline
\end{tabular}


responses. For example, they felt confident that they could learn the most basic elements of the course $(M=6.03, \mathrm{SD}=$ 1.18), but this confidence dropped when the content was a more complex one $(\mathrm{M}=5.11$, SD = 1.48). Interestingly, $48.4 \%$ of students disagreed with the statement that they can get a good grade in this course.

- Affective dimension

Students obtained the lowest mean score of the questionnaire in the Anxiety subscale $(\mathrm{M}=3.81, \mathrm{SD}=1.12)$, indicating that they did not show large amounts of concern on their performance. Yet 38\% of the students thought that their performance on course activities was poor when compared to their peers $(\mathrm{M}=$ 3.69 , SD $=1.78$ ) and $38.7 \%$ reported feeling uneasy during exams $(\mathrm{M}=4.02$, $\mathrm{SD}=1.662)$.

We also assessed if there was any correlation between the subscales of the instrument. There were significant positive correlations between the Motivation subscales. The Intrinsic Goal Orientation correlates with the Task Value subscale ( $\mathrm{r}$ $(339)=0.606, p=0.01)$ and with the Self-Efficacy of Learning and Performance subscale ( $\mathrm{r}(339)=0.597, p=0.01)$. In turn, the latter was positively related to the Control of Learning Beliefs subscale $(\mathrm{r}(339)=0.589, p=0.01)$.

\section{Strategic Learning}

By characterizing this group in terms of their cognitive strategies when studying the first-year Introduction to Calculus module (Table 3), we observed that the effort regulation strategies played an important role $(\mathrm{M}=5.2, \mathrm{SD}=1.05)$. Thus, students perceived their ability to control attention and effort positively. Rehearsal strategies and activation to a more basic level of information was perceived as less relevant to their learning process $(\mathrm{M}=3.95$, $\mathrm{SD}=1.24)$.

\section{- Cognitive and Meta-Cognitive Strategies}

In the Meta-Cognitive Self-Regulation subscale, students demonstrated awareness at the lack of understanding of content. Thus, 93.8\% reported they would go back in the module's contents when they identified some confusion or doubt, and a further $81.4 \%$ were able to identify concepts that were not clear to them during the learning process. This was particularly relevant when considering that $38.9 \%$ of them reported that they did not understand some of the content that had been covered by this module.

Regarding the Elaborative strategies, which were located in the middle range of complexity for this group, students considered relevant making relationships within the course material; either with prior knowledge $(\mathrm{M}=5.27, \mathrm{SD}=1.5)$ or by relating the concepts of the different lectures of the module $(\mathrm{M}=5.12$, $\mathrm{SD}=1.47)$. About $70 \%$ of them reported using this strategy with both existing and new knowledge. In relation to Critical Thinking, also in the middle range, one of the most used strategies by the sample was to think about their own ideas in relation to the learning of the module $(M=5.05$, SD = 1.419). Regarding Organization, $81 \%$ of the students said that one of the most used strategies was to reviewing content and identifying important ideas $(\mathrm{M}=5.66, \mathrm{SD}=1.42)$. In contrast, making diagrams or charts was the least used strategy $(\mathrm{M}=4.51, \mathrm{SD}=$ 1.62). Finally, although this group used Rehearsal strategies less, about half of the students reported reading their notes several times $(\mathrm{M}=4.51, \mathrm{SD}=1.62)$.

- Resource Management

Within the Resource Management subscale, a group of the students scored higher on the subscale of Effort regulation.
About $78 \%$ persisted in the learning of contents considered difficult or boring. Referring to Time and Study Environment, it was also in a high range since virtually all students (92.8\%) attended the lectures and $75 \%$ answered "very true" to that particular statement. However, more than half the group (58.6\%) said it was difficult to successfully achieve a study schedule. Regarding the search of help through peer learning, this group was located in the middle range. When facing difficulties in understanding the module's material, $80.3 \%$ of the students sought help from a peer, while $26.2 \%$ resorted to the teacher. In the subscale of Peer Learning, 67\% studied with classmates for this particular module.

When exploring correlations, it appeared that within the Strategy section, the Meta-cognitive Self-Regulation subscale correlated with several of the subscales of the section, such as the Elaboration subscale $(\mathrm{r}(339)=0.698, p=0.01$ ), the Organization subscale $(\mathrm{r}(339)=0.525, p=0.01)$, and the Critical Thinking subscale $(\mathrm{r}(339)=0.561, p=0.01)$. It was also correlated with Effort Regulation ( $\mathrm{r}(339)=0.560, p=0.01$ ) and the Time and Study Environment subscale (r (339) $=0.500, p=$ 0.01 ). It should be mentioned that several of the subscales that correlate with Meta-cognitive self-regulation were interrelated. In addition, the Peer Learning subscale correlated positively with the Help Seeking subscale (r $(339)=0.517, p=0.01$ ). Finally, it is important to note that the only significant correlations between subscales of different sections of the questionnaire were observed between the subscales of Intrinsic Goal Orientation and Critical Thinking ( $\mathrm{r}(339)=0.525, p=0.01)$.

\section{Discussion}

The study sought to characterize the motivational and cognitive learning strategies of first-year undergraduate students from the Civil Engineering degree course at UC, as seen through those who undertook the module of Introduction to Calculus during the first semester of 2011. They were a group of students that faced challenges associated with the transition from secondary school to university-level higher education (Susperreguy et al., 2007), which made this group particularly interesting for research purposes. According to the findings of this study, students showed higher scores on motivational than cognitive dimensions associated with their learning experience of this module.

By characterizing this group as to their motivational profile in particular, it was found that students engaged in learning tasks of the course and learning challenges involved, rather than the single assessment or grade. Learning was almost as important for them as the results, although the latter was to a lesser extent. In this sense, students did not separate the two in their learning and valuing of the module, which according to Romero \& Perez (2009) would positively affect their motivation and the quality of their learning experience and outcomes. These findings could be used in the future for advancing the current teaching style of the module and other aspects of the Engineering curriculum.

An interesting aspect was that most students perceived this module as an important and useful tool. In addition, they hoped that their efforts (rather than external variables) could positively affect their learning outcomes, showing that they recognized their role and opportunities to intervene. This was very relevant given that they were novice students in their first curricular year and they needed to match expectations with actual performance. Aspects like giving value and meaning to the tasks of the module, 
and feeling that their efforts were not meaningless were significant dimensions. Moreover, according to their strategies for studying Introduction to Calculus, this group would stand to regulate their efforts and focus on the study by monitoring the concentration and strategies employed. They were aware of their learning process and were also able to monitor it and to be conscious of their comprehension and understanding. Findings from this study suggest that these students are highly selfregulated and proactive in their learning process (Zimmerman, 2002).

In their study process, they used more strategies of Elaboration or Organization than that of Rehearsal. Thus, they prefer to use strategies related to association and integration of information, especially such strategies which are most relevant. Hence, they used more active and complex strategies in their learning. By managing their time and their learning environment, these students cared for their attendance to the lectures and also the environment where the learning process took place. However they also had some difficulty with organizing their time. Regarding their learning resource management, although about half of them studied with peers, this was more often reported when they were experiencing difficulties with their learning process, and not as part of their learning routine. Very few of them reported asking the module's leader or other lecturers for help when needed.

Although sections of the Motivation and Strategies were analyzed separately, it was difficult to separate both aspects in the learning process. This was particularly true when considering the role of motivation in higher levels of effort associated with a more autonomous learning process (Romero \& Pérez, 2009). The correlations found reinforce the strong interrelationship between these components. For example, there was a significant correlation between Intrinsic Motivation and Critical Thinking, both of which typically involve active learning processes. Critical thinking involves cognitive tasks like using information for solving problems or making critical evaluation with respect to standards of excellence (Pintrich et al., 1991). Probably implies participating in the task because of intrinsic goals such as the challenge implied in it. That is why the correlation observed between this sub scales is so interesting, as it reinforces the importance of being an active learner from both motivational and cognitive dimensions of the learning process.

A second example was the important role of Meta-cognitive self-regulation. As it increased, more complex strategies like active learning and better management of resources were observed.

The fact that these students valued the learning process without neglecting their results, poses significant challenges with respect to the teaching-learning process. This is not only in terms of supporting them when expected positive results, such as high grades, are not achieved, but also in enhancing their motivation for learning new material, and developing new strategies that might be more effective in their learning experience and performance.

The literature indicates that self-regulation in learning is not a static trait, but rather a process of adaptation to academic tasks (Zimmerman, 2002). Moreover, it has been suggested that the context and environment in which the learning process takes place should be further investigated (González et al., 2002). For example, this study could be replicated in subsequent academic years for the same sample of students. Future studies could also consider further aspects, such as assessing changes in the motivations of students and variations in the strategies employed to study, both over time and between subjects. This studies should, specially consider the interrelation of variables implied in the study (Hojas et al., 2012), and the relation between motivational and cognitive aspects, as we found in this study. Qualitative studies could also expand the findings of this study, exploring the learning experience in more detail, as seen through both students and teachers.

This study faces some challenges and limitations. The instrument was applied in one of the last sessions of the semester in a lecture that had voluntary attendance. Although the results indicate that in this group class attendance was highly valued, it is possible that those who participated in the study were precisely the students who value the attendance higher. Therefore, there is the risk of selection bias in this study, which should be further investigated in the future using different sampling and recruiting techniques. Interestingly, the MSLQ questionnaire behaved similarly as when it has been used for its original application. This was observed after the estimation of the reliability test. Despite its challenges and limitations, this study has contributed relevant knowledge on first-year Civil Engineering undergraduate students' approach to learning. Our findings highlight the significance that motivation and cognitive learning strategies have in these early-career students, and the close relationship that exists between the two of them. Both motivational and cognitive learning strategies affect the learning experience in the university context and later learning outcomes and, therefore, should be taken into account when developing and assessing modules and broader curricular aspects in higher education.

\section{Conclusion}

The learning process is sensitive to the demands from the task and the specific subject of study. This study provides a characterization of the motivational and cognitive learning strategies used by students in their first year of undergraduate Civil Engineering degree course at a prestigious Chilean university. The module considered for this study was Introduction to Calculus, which corresponds to the very first course in Mathematics these students undertake at university. Our findings indicated that students reported high motivational strategies, particularly regarding their value of the task and their control of learning beliefs. These were ranked as "high" level. As for the cognitive learning strategies, they were also high but slightly lower than the motivational dimensions of the learning experience. Hence, they were ranked in an upper-middle range, excelling in meta-cognitive self-regulation and regulation of their effort. Moreover, motivational and cognitive strategies were interrelated components affecting the learning outcomes, as perceived by the students included in this study. These results contribute to a better understanding of the learning process of Civil Engineer students in an early curricular stage, thereby providing relevant information that could be applied in other teaching and learning practices in higher education.

\section{Acknowledgements}

We acknowledge the support of the School of Engineering at the Pontificia Universidad Catolica de Chile. We are particularly grateful to the lecturers of the Introduction to Calculus module, for their commitment to this study. We also thank Dr. Luis Villarroel del Pino, for his valuable contribution to the data analysis, and Dr. Christo Albor for his valuable review to 
this manuscript.

\section{REFERENCES}

Chi-Kin Lee, J., Yin, H., \& Zhang, Z. (2010). Adaptation and analyses motivated strategies for learning questionnaire in the Chinese setting. International Journal of Testing, 10, 149-155. doi:10.1080/15305050903534670

Chiecher, A., Donolo, D., \& Rinaudo, M. (2007). Aprendizaje virtual en asignaturas presenciales incidencia sobre la motivación y el uso de estrategias. Revista Virtual Udesc Virtual, 1, 1-24.

García, T., \& McKeachie, W. (2005). The making of the motivated strategies for learning questionnarie. Educational Psychologist, 40, 117-121. doi:10.1207/s15326985ep4002_6

González, R., Valle, A., Rodríguez, S., \& Piñeiro, I. (2002). Autorregulación del aprendizaje y estrategias de estudio. In J. Pineda, J. Nuñez, L. Álvarez, \& E. Soler (Eds.), Estrategias de Aprendizaje. Concepto, evaluación e intervención (pp. 17-38). Madrid: Ediciones Pirámide.

Hojas, A. M., Anais, M. J., Bustos, A., Letelier, C., \& Zuzulich, M. S. (2012). Requerimientos académicos en estudiantes universitarios: El camino recorrido por el centro de apoyo al rendimiento académico y de exploración vocacional de la UC. Revista Calidad en la Educación, 36, 249-263.

Letelier, C., Lissi, M., Flores, A., \& Assef, C. (2007). The Motivated Strategies Learning Questionnaire.

Paoloni, P. (2009). Contextos favorecedores de la motivación y el aprendizaje. Una propuesta innovadora para alumnos de ingeniería. Electronic Journal of Research in Educational Psychology, 7,
953-984.

Pintrich, P., \& García, T. (1993). Intraindividual differences in students' motivation and self regulated learning. German Journal of Educational Psychology, 7, 99-107.

Pintrich, P., Smith, D., García, T., \& McKeachie, W. (1991). A manual for the use of the motivated strategies for learning questionnaire (MSLQ). Ann Arbor, MI: University of Michigan.

Rinaudo, M., Chiecher, A., \& Donolo, D. (2003). Motivación y uso de estrategias en estudiante universitarios. Anales de Psicología, 7, 107-119.

Rinaudo, M., De la Barrera, M., \& Donolo, D. (2006). Motivación para el aprendizaje en alumnos universitarios. Revista Electrónica de Motivación y Emoción, 9.

http://reme.uji.es/reme/numero22/indexsp.html

Romero, M., \& Pérez, M. (2009). Motivar a aprender en la universidad: Una estrategia fundamental contra el fracaso académico. Aportaciones de la investigación y la literatura especializada. Revista Iberoamericana de educación, 50, 1-13.

Schunk, D., \& Zimmerman, B. J. (2009). Motivation and self-regulated learning. Theory, research and applications. New York: Routledge.

Susperreguy, M. I., Flores, A., Micin, S., \& Zuzulich, M. S. (2007). Apoyo académico en la educación superior: descripción de la experiencia y perfil de los alumnos que participan en el CARA UC. Revista Calidad en la Educación, 26, 307-333.

Zimmerman, B. (2002). Becoming a self-regulated learner: An overview. Theory into Practice, 41, 64-70. doi:10.1207/s15430421tip4102_2 